\title{
Journal of the Association for Information Systems
}

Volume 18

Issue 12 Special Issue: Information and

Communication Technology for Development

(ICT4D): The Next Grand Challenge for IS

Research

$12-31-2017$

\section{Flipping the Context: ICT4D, the Next Grand Challenge for IS Research and Practice}

\author{
Sundeep Sahay \\ University of Oslo, sundeeps@ifi.uio.no \\ Maung K. Sein \\ University of Agder, Maung.K.Sein@uia.no \\ Cathy Urquhart \\ Manchester Metropolitan University, c.urquhart@mmu.ac.uk
}

Follow this and additional works at: https://aisel.aisnet.org/jais

\section{Recommended Citation}

Sahay, Sundeep; Sein, Maung K.; and Urquhart, Cathy (2017) "Flipping the Context: ICT4D, the Next Grand Challenge for IS Research and Practice," Journal of the Association for Information Systems, 18(12), . DOI: $10.17705 / 1$ jais.00478

Available at: https://aisel.aisnet.org/jais/vol18/iss12/5

This material is brought to you by the AIS Journals at AIS Electronic Library (AISeL). It has been accepted for inclusion in Journal of the Association for Information Systems by an authorized administrator of AIS Electronic Library (AISeL). For more information, please contact elibrary@aisnet.org. 


$$
\begin{aligned}
& \text { Tournal of the } \\
& \Lambda_{\text {ssociation for }} \text { nformation } S^{\text {ystems }}
\end{aligned}
$$

\title{
Flipping the Context: ICT4D, the Next Grand Challenge for IS Research and Practice
}

\author{
Sundeep Sahay \\ University of Oslo, Norway \\ sundeeps@ifi.uio.no \\ Maung Kyaw Sein \\ University of Agder, Norway \\ Luleå University of Technology, Sweden

\section{Cathy Urquhart} \\ Manchester Metropolitan University, United Kingdom
}




\section{Introduction}

We often talk about a flipped classroom in online learning, which flips the traditional concept of learning on its head. As senior editors for this special issue on "Information and communication technology for development (ICT4D): the next grand challenge for information systems", we asked ourselves: "What if we flipped the context of ICT4D research on its head? What if we reimagined ICT4D not simply as a niche area for IS, but as an opportunity for learning for mainstream IS?". We sought not only to showcase highquality ICT4D research but also to demonstrate that this area of research has come of age and can contribute to all IS research. Thus, this special issue focuses on 1) improving how we understand "development" as more than an arena for empirical research and instead as a vehicle to substantively analyze how ICT can foster it and 2) challenging authors to identify learning in their work in the ICT4D discipline that could inform and contribute to the evolution of the broader IS discipline.

The first focus responds to various scholars' calls (e.g., Orlikowski \& lacono, 2001; Davison \& Martinsons, 2014) to be more precise about both the primary object and context of research in general. The second focus stands in stark contrast to earlier recommendations (Walsham, 2017) that the ICT4D discipline should engage with and learn from theoretical and methodological developments in mainstream IS. The emergence of "reverse innovations" from which mainstream IS can learn from ICT4D research not only reflects the steadily increasing maturity of the ICT4D discipline but also highlights the importance of development as a phenomenon, that concerns each and everyone in the world and not only those living in so-called "developing countries". Thus, this special issue is timely given a global context that features great complexity, uncertainty, and new challenges (e.g., security, migration, and, climate change to name a few) and the IS discipline's need to cumulatively evolve to better support these challenges. We hope we can inspire more IS researchers to consider this changing global context and join ICT4D researchers in a quest to achieve social impact beyond the traditional confines of IS research. By conveying this important message through this journal's pages, we hope we can help to galvanize a larger community of researchers to contribute to both the research and practice of ICT4D.

The paper proceeds as follows. In Section 2, we briefly trace the historical evolution of the two domains (ICT4D and mainstream IS), which, despite attempts to develop closer links between the two, many researchers see as following divergent paths. In Section 3, we argue that this is dichotomy is false and suggest that we adopt a more synergistic view that the IS research community take on ICT4D as a "grand challenge". In Section 4, we describe the process of how this special issue came into being and introduce the four papers in the issue, which all focus on the conceptualization of development and the emerging reverse innovations. In Section 5, we discuss the systemic challenges that researchers in ICT4D experience and how we need to address them to make research contributions more relevant and insightful for the IS discipline as a whole.

\section{A Brief Historical Overview of the ICT4D and Mainstream IS Research Disciplines}

\subsection{ICT4D Research}

We refer to ICT4D research as the body of studies that analyzes the complexities and conversation surrounding the role of ICTs in the development of low- and middle-income countries (LMICs), which development discourses also refer to as "the Global "South" ${ }^{1}$. In the conceptual and theoretical

\footnotetext{
${ }^{1}$ The North-South divide is the socio-economic and political division that exists between the wealthy developed countries, known collectively as "the North", and the poorer developing countries, collectively known as "the Global South". Most North nations reside in in the Northern Hemisphere and mostly cover the West (called the First World) and many of the East European countries (called the Second World). All the members of the Group of Eight (G8) are from the North. On the other hand, the "Global South" has a more vague definition and is generally held to refer to the "Third World" (i.e., Africa, Latin America, and the developing countries in Asia). It is a useful metaphor because it emphasizes the interconnected histories of many countries and the multiple reasons why large inequalities between the North and South persist. Researchers deem nations that do not qualify for "developed" status as part of the South, and such countries mostly reside in Africa, South America, Asia, and the Pacific Islands (also called the Third World). Researchers often view the North-South divide as a political division to facilitate targeting of aid flows. The term "divide" has more recently been renamed "development gap" which shifts the emphasis on how poorer countries move closer to richer countries. As countries become developed, they may become part of the North regardless of geographical location. The Human Development Index provides a good measure for which side of the gap a country resides in. The nearer a country's score is to 1.0, the greater its level of development and the further it is on its development pathway. For a succinct overview, see https://www.rgs.org/NR/rdonlyres/6AFE1B7F-9141-472A-95C1-52AA291AA679/0/60sGlobalNorthSouthDivide.pdf
} 
frameworks of ICT4D and empirical research, researchers seek to understand the challenges provided by the socio-political context of ICT use in developing countries. The concerns are not just technical; they also include social, organizational, economic, legal, and ethical aspects. At the heart of ICT4D research concerns the question of whether ICTs actually contribute to development. In the words of Geoff Walsham (2005, p. 8), "we should be trying to make a 'better' world with ICT". In our experience, most ICT4D researchers acknowledge the role of their own values in their work, or, to paraphrase Walsham again, they acknowledge that one cannot simply measure a better world with ICT in in economic terms-such a world also involves a wider global agenda of social and spiritual welfare (Walsham, 2005).

To trace some of the historical underpinnings of this discipline, we draw on Walsham's (2017) recent review in which he identifies three broad periods of evolution. In the first period (mid-1980s to mid-1990s), known as the "early beginnings", the ICT4D discipline formally began at least in so far as journals published formal ICT4D research and authors presented such research at conferences. The Information Technology for Development Journal (ITDJ) began publishing in 1986, and the first IFIP W.G. 9.4 conference on social implications of computers in developing countries was held in New Delhi, India, in 1988. Walsham notes that researchers broadly took the research themes they discussed in this period from mainstream IS research, such as the significance of context, the need for indigenous development, and the recognition that technology is only one element of broader change efforts. Researchers also began to examine the meaning of "development" by drawing inspiration from a parallel debate in the reference development studies discipline. The conceptualization of development began to move beyond the dominant perspective of "modernization" (i.e., developing countries should strive to become like developed countries by emulating the path followed by the latter) towards the current view of alternative trajectories of development. A more popular view of development in ICT4D is rooted in Amartya Sen's (1999) conceptualization of development as freedom of choice. In this view, development should enlarge people's choices and remove the power of oppressors. ICT's role is to enhance this freedom by building the capabilities of individuals and the society in which they live. The paradigm is that of human development, and the most commonly used theory for human development is the capability approach (Sen, 1999). ICT4D researchers have increasingly adopted this paradigm of development (Sein \& Harindranath, 2004, Thapa, Sein, \& Sæbo, 2012, Avgerou 2017).

The second period (mid-1990s to mid-2000s), termed as "expanding horizons", saw the enhanced use of ICTs for development, which the Internet's proliferation largely fueled. The theme of understanding "development" went beyond purely economic and market concerns to draw instead on the interdisciplinary research approaches that gained prominence in this period.

The third period (mid-2000s to present), known as the "proliferation", saw the dramatic expansion of ICT use for development-fueled to a large extent by the spread of mobile technologies to all sections of the population. This expanded use of these technologies significantly impacted the lives of the poorest. In addition, ICT4D research started to contribute to the area of development and development studies. For example, Thapa et al. (2012) examined "collective capability" to address the criticism of Sen's focus on the individual in his capability approach. Seen in this light, ICT4D research is also an "outreach" activityit seeks to contribute to development studies by explicitly introducing the role of technology (and specifically ICT) into the discourse.

In closing, Walsham (2017) identifies some topics of future relevance for the ICT4D discipline, which includes systemic poverty, global health, humanitarian crises, and the dark side of ICTs. The underlying and sustaining focus in these areas of research remains the challenge for IS researchers, which Walsham (2005) first raised over a decade ago, "to make a 'better' world with ICT". Other scholars have continued in this vein. For example, Avgerou (2017). Sahay (2016) and Qureshi (2016) published papers in ITDJ on the same topic. We expect this question to be of increasing relevance to both ICT4D and mainstream IS in the future as ICTs become more pervasive and permeate all aspects of our everyday work, personal, and social lives.

\subsection{Mainstream IS Research}

"Mainstream" IS research, on the other hand, typically focuses on the managerial concerns of how IT supports, enables and influences the effectiveness and competitiveness of enterprises that typically reside in developed countries in North America and Europe (referred to as "the North" in development literature). In current times, such countries as India, China, and Brazil have also gained the attention of mainstream research efforts; however, this research has typically not focused on development-related concerns but on the experiences of businesses that operate in developing countries, which the growth in outsourcing research exemplifies (Sahay, Nicholson, \& Krishna, 2003). Various factors typically drive mainstream 
research concerns, such as the need to expand efficiencies, how new and emerging technologies promise new benefits, the challenges posed in attempting to adopt them, and the benefits that accrue (or not).

Scholars have presented various accounts in the IS discipline overall (Davis, 2006; Hirscheim \& Klein, 2012) and those related to specific "non-developing" countries such as the UK (Land, 2014) and Australia (Clarke, 2006). The research generally agrees that the IS discipline began in the 1960s (Davis, 2006) and that its origins lay in computer science, which itself originated in the 1940s. IS research has primarily studied technology in organizations (mostly business entities). The first IS educational program was established in Minnesota in 1968. It was only in 1976 that the IFIP organized Technical Committee 8 (which focuses on IS issues) and, thus, formally recognized IS as a separate discipline in computing. Davis (2006) has attributed this time lag between the origins of computer science and recognition of the IS discipline to the absence of interesting issues in IS research (beyond data processing) and the greater diversity of IS researchers who come from such diverse disciplines as business studies and its sub-groups of accounting and finance. The mainstream IS discipline was far from homogenous: researchers in the UK, Scandinavia, and US all took different perspectives.

In tracing the history of mainstream IS, Hirschheim and Klein (2012) identified four periods, which starts with the "first era" (i.e., from inception to the mid-70s) when the first IS educational program and TC8 were established. The discipline evolved in business schools in the US and informatics departments in Europe. In terms of research, "systems" represented a dominant theme, which included inquiring systems (Churchman, 1987), hard systems (Langefors, 1977), socio-technical systems (Mumford \& Weir, 1979), soft systems (Checkland, 1981) and decision support systems (The Minnesota School). The "second era" (i.e., mid-1970s to mid-1980s) saw the growth of personal computers and the enhancement of computing power, which the Japanese Fifth Generation Computer Project reflected. The premier conference in the discipline, the International Conference on Information Systems (ICIS), began in 1980 and the premier IS journal MIS Quarterly launched in 1977. The research themes that research addressed in this era broadly concerned the environment or context of IS projects (captured in Kling's (1980) Web model), the different problem areas that IS address, the impacts of IS (Delone, 1988), and the role of users, which the later popularity of the technology acceptance model (Davis, 1989) and the growth of participatory design methods reflected. The "third era" (mid-1980s to mid-1990s) saw the rise of personal and departmental computing, which brought to the fore new research challenges; namely, data incompatibility, integration, connectivity, and data integrity. With organizations' increasing investments in IS applications, there was heightened interest in understanding how IS strategies could better align with business strategies and concerns around the productivity paradox. The dramatic rise of research on outsourcing reflects concerned both strategies and investments. The "fourth era" (mid-1990s to today) is being shaped by the commercialization of the Internet and the growth of the globalization phenomenon. Cross-cultural issues have gained increasing attention, which has created overlaps with developing country research, which operates in a different context. Researchers have expressed growing existential anxiety about the IS discipline's relevance and place, which Markus's (1999) question "What happens if the IS discipline as we know it goes away?" typifies. In essence, this question asks whether IS research is making things better and whether we should view our research as IS for "something".

\subsection{What Do These Histories Tell Us?}

At a macro level, these abridged historical accounts of the two disciplines show that they have distinctly different origins and trajectories of evolution. The research agendas of mainstream IS, itself a function of its origins in business schools in North America, highlight a dominant techno-centric or technologically deterministic and rational perspective. On the other hand, given the ICT4D discipline's primary concern on development and that its founding researchers primarily came from Europe, a social sciences perspective (which focuses on issues of context and draws on an interpretive tradition of case-study based research) dominates the discipline. For ICT4D researchers, case studies in context have long been the dominant mode of inquiry. In contrast, mainstream IS researchers are to a great extent positivist oriented and primarily focus on lab experiments and survey analysis. Arguably, conducting case studies tends to be more time consuming and involves greater travel and budget requirements (compared with conducting lab experiments; conducting surveys often requires considerable resources). As a consequence, such an approach can be less rewarding in terms of submitting publications to "high-profile" journals. Thus, ICT4D and mainstream IS researchers have tended to publish in different journals and, thus, contribute to different trajectories of research and focus. Mainstream IS research concerns have primarily remained those of the developed world (the "North"), while ICT4D research has by definition focused on the developing world (the "South") as its empirical setting. In each, research communities have evolved along 
these lines with separate conferences and publication outlets. Even when mainstream IS has shifted its research gaze to the South, it has remained focused on the concerns of the developed countries. Outsourcing research is a prime example because, although conducted mostly in LMICs, its perspective is that of the benefits derived for enterprises in developed countries.

Thus, on first impression, one can view the two streams to have diverged. Mainstream IS research remains the "convention" while ICT4D has happily settled into its own world of niche conferences and journals. That said, we have seen the focus of mainstream IS research move beyond organizations towards a more social agenda. The theme of ICIS in 2013 and 2014 was "reshaping society through information systems design" and "building a better world through information systems", respectively. The advent in the past few years of AIS SIGS that focus on green IT, social inclusion, and global development represents more socially conscious strands of research in the discipline.

\section{Towards a Synergistic View}

From the preceding sketches, one may easily deduce that ICT4D and mainstream IS research represent diverse areas with little in common. We contend that this view is myopic and comprises a false separation between developed countries and LMICs to the detriment of both. This separation denies all the vast potential for synergistic learning in a variety of research settings whether developed or not. Take, for example, the topic of e-government: research on this topic focuses on how ICT can, or has the potential to, transform the relationship between government and citizens. Specifically, this research looks at issues related to providing better services to citizens, providing better governance, and increasing citizen participation. While a vast body of research exists in e-government, the empirical setting has, in the main, been developed countries. However, we have much to learn from e-government research in LMICs that we can apply to developed countries. LMICs are rapidly adopting e-government initiatives (often out of necessity, although they do so also for other reasons such as modernization or the sheer influence of funding and aid agencies). The weaker and different socio-economic context of LMICs, which often feature a less open and relatively unstable political climate, has fostered many innovative approaches to e-government. Innovations in the developing world have occurred in other areas as well, which mobile technology has driven to a great extent. For example, Kenya has led the world in mobile payments for almost a decade - technologies that are just taking shape in the US and Europe.

The more developed countries can learn much from these innovations. Moreover, sizeable pockets of underdeveloped areas exist in the developed world; indeed, developed countries still need to address extreme social deprivation in some urban and rural settings. Qureshi's (2015) work in the deprived neighborhoods of Omaha in US is a good example. At the very least, the more complex context of underdeveloped areas and LMICs provides a rich arena for theory building and testing for IS researchers, a point emphasized by Avgerou (2017). The transformational potential of ICT could initiate fundamental and structural changes, which, in turn, could increase our understanding of the role of the intertwined relationships between ICTs, organizations, and society.

This potential for cross-fertilization has not gone unnoticed. Some ad hoc attempts have been made to bring synergies between these two domains of research. For example, in 2005, the IFIP 9.4 (on Social Implications of Computers in Developing Countries) and IFIP 8.2 (Organizational Implications of ICTs) held a joint conference in Athens, Greece, in order to develop such synergies. The establishment of the AIS Special Group on Global Development in 2008 (SIGGlobDev) is a further step in this direction. With the same aims, we have seen special issues of mainstream IS journals such as MIS Quarterly and The Information Society on IS in developing countries. However, such efforts have been too few to create the required momentum for the two research domains to mutually contribute systemically. The interest in ICT4D has remained minimal in mainstream IS. Through this special issue, we argue that these efforts towards synergy need to be reinvigorated rather than allowed to fade away, which would leave domain to continue to pursue their respective aims. If the broader IS research community is to better respond to the challenges that face the world today and evolve into a unified body of knowledge (Hirscheim \& Klein, 2012), we urgently need to explicitly try and build these synergies. This special issue does as much but with an important difference. In our view, we can better achieve the synergies by challenging the traditional model of knowledge flowing from the mainstream to the "periphery". Instead, we put the case that reverse innovations from so-called "niche" disciplines such as ICT4D are both possible and desirable. In short, we are "flipping the chart". 


\section{Papers in this Special Issue}

In the call for papers, we invited papers that examine the mutual synergy and cross-fertilization potential between ICT4D and mainstream IS research. We set two strict criteria: first, papers must have LMICs or underdeveloped areas in the developed world as a primary focus. They must emphasize how ICTs can foster development. Second, papers should clearly elaborate how the lessons learned from the papers can inform and transform mainstream IS research.

We invited prospective authors to send in abstracts so that we could give feedback on how to develop them further into full papers or advise on whether the envisaged paper would fit into the special issue's focus. We did not intend this process to filter submissions but to introduce a developmental stage for authors. In total, we received 58 submissions, a healthy figure that reflects the extent of ICT4D work in our discipline and perhaps also a perceived lack of outlets for ICT4D in mainstream IS journals. We sent the 19 papers that passed editorial screening out to at least two reviewers in the first round. We selected these reviewers-experienced and well-published researchers from both ICT4D and mainstream IS areas-from an editorial review board that we set up for the special issue. We then sent the reviewers' reports directly to the authors after which they could respond to the reviewers' comments and to describe the strategy they would adopt to address the concerns raised. This innovative approach to review gave us, as guest editors, more information on which to assess the authors' ability to engage with and respond to the review process. We then read the authors' responses and the reviewers' comments together to decide which papers we would advance to the next round. Twelve papers made the cut. We followed the same process in the second round after which we advanced six papers to the final round. Out of the six, all of which were impressive, we selected four for the special issue. In our opinion, these four papers are particularly strong in contributing to our aim of distinct reverse innovation. We hope that both ICT4D researchers and mainstream IS researchers alike will widely cite these papers. The first paper, "Exploring the Dialectics Underlying Institutionalization of IT Artifacts" by John Alver Dobson and Brian Nicholson, is a case study that analyzes the problems related to IT introduction in micro-enterprises in a rural village in Mexico. The authors contextualize the case through reviewing institutions in Mexico and the "e- Mexico" government policy to stimulate increased penetration of IT usage based on espoused development goals. The paper highlights the contradictions between the introduction of IT artifacts (specifically mobile phones, an Internet-based ordering system, and digital catalogues) and local historically embedded social and cultural institutions. The paper focuses on how one can resolve contradictions through the lens of dialectics between each side of the contradiction and the active praxis that impacts on the use or rejection of the IT artifact. The paper contributes to discourses around human-centered approaches to development with a focus on the freedom of individuals to improve their lot in life while also acknowledging the institutional conditions and constraints that exist. The use of the dialectical lens to examine the institutionalization of IS innovations and how these innovations are intertwined with contestation processes are important contributions to mainstream IS research.

The second paper, "The Doing of Datafication (and What this Doing Does): Practices of Edification and the Enactment of New Forms of Sociality in the Indian Public Health Service" by Seamas Kelly and Camilla Noonan, examines the question of the role of data in organizational innovation. The setting is health information systems in India, and the authors focus on the efforts made to use data for grass roots decision making. The authors take a unique performative, practice-based approach to theorizing data practices and distinguish between two broad forms of such data practices: datafication and the "edifying" practices of datafication, which involve data's being enacted or performed in different ways. Through their case study of a state government agency and the fascinating story of an individual in that agency, they explore the power of these different kinds of datafication practice and demonstrate how each is deeply implicated in the (re)production of different forms of human sociality. Describing these socialities as "authoritarian bureaucratic" and "dialogic", they explore the distinctive kinds of moods and affectivities generated: they argue that the social and organizational dynamics that they depict should be recognizable to those with no experience of LMICs or the Indian health system. The paper contributes to all organizations that engage in data-led initiatives, including big data analytics, by encouraging one to examine deeply what people do with that data.

The third paper, "Insights from an ICT4D Initiative in Kenya's Immunization Program: Designing for the Emergence of Sociomaterial Practices" by Isaac Holeman and Michael Barrett, addresses the developmental challenge of providing improved healthcare through a case study of the cold storage of vaccines in Kenya in which ICT played a vital role. The study provides a fresh perspective on the longstanding concern with local context in ICT4D research. The authors' contribution to mainstream IS 
research lies in their revealing specific activities through which designers may guide the emergence of socio-material practices. The premise for these activities is based on the concepts of material back talk and break down. In doing so, the authors draw on established concepts and theories of mainstream IS research. Through insights from their case, they contribute to the discourse on these concepts and the practice of design, especially contextually aware design research frameworks. For practitioners, focusing on practice break downs and material back talk can help them grapple with the complexities of the implementation bottleneck in global health and development.

The fourth paper, "Health Information Systems and Accountability In Kenya: A Structuration Theory Perspective" by Roberta Bernardi, examines how the information generated by health information systems becomes a means of accountability that is more meaningful to government and aid agencies than to those who are responsible for local health services. Using a theoretical perspective developed from structuration theory and the technology domain of HIS, she analyzes the emergence of local accountability practices. The developmental challenge Bernardi addresses is the same one that Holmen and Barrett address; namely, the improvement of healthcare in developing countries. The paper informs mainstream IS research by addressing a longstanding criticism of the research stream that uses structuration theory; namely, that technology and materiality has a limited, if any, explicit role in structuration. By combining structuration theory and materiality, this paper provides a sharper interpreting lens for the mainstream IS research community.

\section{Grand Challenges for IS Research: How Do We Approach Them?}

The papers in this special issue identify challenges that concern the use of information to improve health management (Kelly \& Noonan, 2017), the contradictions inherent in ICT-enabled change efforts (Dobson \& Nicholson, 2017, the design of ICTs to enable the emergence of socio-material practices (Barrett \& Holmen, 2017), and the relationship between structure and agency in the context of the implementation of health information systems (Bernardi, 2017). These identified challenges are not unique and do not apply only to ICT4D. They do, however, represent problems that the IS discipline faces. A mainstream IS journal could have easily published all of the papers. The discerning reader will note that three of the four papers focus on ICT initiatives in the health sector; while purely coincidental, it also serendipitously highlights the relevance of ICT4D research for health, which has been made a major priority in the UN's sustainable development goals (SDG). Indeed, these papers contribute to making the world a better place.

Taken together, the papers in this special issue send the message that research in ICT4D is not an outlier or an exotic niche but very much a part of mainstream IS research. Research in both domains analyzes similar issues, knowledge gaps, and empirical problems and look to similar theories. By the same token, such research contributes to discourses on these very same issues and theories. At the very least, these papers show that the apparent divergence between ICT4D and mainstream IS research is more due to a lack of mutual dialogue than of substance. The relationship between context and generalization is intricate and at times dialectical. As Davison and Martinsons (2016) and Avgerou (2017) point out, a good understanding of context is essential for good theory building in our discipline. The ICT4D dimension of the papers shows how the authors' understanding of context informed their research. Theory building, on the other hand, requires the abstraction of knowledge through de-contextualization. It is this inferential leap from the specifics of settings to the realm of the concepts that informs mainstream IS research. In our opinion, all four papers have met this challenge.

While we have highlighted the similarities, it would also be legitimate to question the differences in the two arenas of research. One can argue that one key difference is that the challenges examined in ICT4D research represent microcosms of empirical contestations from which we can zoom out to analyze broader development processes (e.g., those relating to public health concerns in India and Kenya). A focus on development concerns is not central to mainstream IS research. Thus, while the means for analysis (theories and methods) in both domains may have similarities, the end focus arguably varies. Linked to these varying aims, one can argue that ICT4D researchers are more likely to also understand and question the moral and ethical bass of ICT projects because this basis shapes their contributions to the development agenda and for many intrinsically tied up with social justice issues.

ICT4D research addresses problems that are vital and intricately anchored to practice. In the longstanding (and never-ending) debate on rigor versus relevance, researchers sometimes argue that, while ICT4D research is unquestionably relevant, it may not display the same degree of rigor as IS mainstream research, especially in terms of publication in high-profile journals. Putting aside different interpretations of rigor, the element of rigor may not be well developed in the discipline of ICT4D given its more recent 
origins. However, we argue that weak rigor is a trait that is not necessarily inherent or natural to the discipline. As the papers in this special issue demonstrate, it is possible to combine both relevance and rigor, which more than a decade of longitudinal empirical analysis has often reflected. Through such a combination, the papers in this special issue contribute to debates in mainstream IS research, and the authors have used them to strengthen their own research efforts.

We note above that a regular issue of any mainstream IS journal (including JAIS) could have published all four papers in the special issue. As for why, one reasons is that all the authors are also prominently published in mainstream IS literature. However, we still need to think about how to encourage researchers who publish primarily in ICT4 outlets to contribute to the mainstream IS literature. Some researchers may be content with this status quo and do not wish to "cross over" into mainstream. To them, we reiterate that they implicitly address mainstream IS issues, perhaps inadvertently (likewise the vast majority of researchers in mainstream IS who have no interest in development). However, for those who do wish to contribute to both areas, a way forward is to collaborate to build on the strengths that each bring. For instance, mainstream IS researchers who see the South as the arena for empirical research can collaborate with ICT4D researchers who can bring in their understanding of development. Consider research on outsourcing: while mainstream IS literature focuses on the efficiencies, competitive advantages, and benefits derived for organizations predominantly located in the North, an added ICT4D perspective can shift the focus to the developmental implications of outsourcing

In discussing the similarities and differences between these two streams of research, we should also point out the ways in which research practice varies. Typically, researchers from universities based in the North conduct research in mainstream IS research with a few exceptions. While researchers from the same kinds of institutions conduct ICT4D research, they often have their roots in developing countries (as is the case for two of the three guest editors of this special issue). These researchers (including all three guest editors) have the privilege of straddling both the worlds of mainstream IS and ICT4D. Often, research sites in developing countries tend to be passive providers of data rather than active co-constructors of research insights. Consequently, we have the stark reality that researchers based in institutions located in developing countries make limited contributions to both the mainstream and ICT4D disciplines. Tellingly, none of the authors of the papers in this special issue come from institutions in developing countries. Even though countries such as India and China represent global hotspots of ICT initiatives, research outputs from academics based in these countries is not commensurate with the ICT activity that takes place there. While this special issue does not focus on understanding why, we believe it is important to flag this constraint as it potentially shapes the quality of any developed insights. Arguably, insights developed by researchers who are situated in a context are richer than those developed by researchers located at a distance (both geographically and culturally). Addressing this constraint is a non-trivial challenge because it involves various structural, financial, and institutional conditions. For example, developing countries often have limited access to literature and communities of practice and even basic training in information systems (compared with computer science education). Some positive steps have already been taken. For example, AIS adjusts membership fees based on the Human Development Index. More can be done to support researchers based in the South; an audit of research interests and of home country of AIS members could be a good first step in appreciating the diversity of members and the research they do.

In highlighting some of these similarities and differences, we do not seek to intellectually "other" either of the disciplines; on the contrary, we need to understand what contributes to this perceived "othering" (as is the case today) (namely, practice-based constraints) and to acknowledge and try to address them. Building meaningful partnerships between researchers (both North-South and South-South) is key to addressing these constraints. Given this concern, we are glad to note the next IFIP W.G. 9.4 conference to be held in Tanzania in 2019 has "strengthening Southern-driven cooperation as a catalyst for ICT4D" as its theme.

This special issue focuses on stimulating and reigniting this interest by advocating ICT4D as the next great challenge for IS research. We live in a global world with global concerns. Many researchers also see a role for IS in furthering important social agendas such as the alleviation of poverty and the combatting of climate change. In our view, the ubiquity of technology and the way it is intertwined with every aspect of human life only increases our obligation to engage with ethical and justice concerns, including understanding what we mean by ICT4D. We should indeed be making a better world with ICTs. 


\section{References}

Avgerou, C. (2017)). Theoretical framing of ICT4D research. In J. Choudrie, S. Islam, F. Wahid \& J. Bass (Eds.), Information and communication technologies for development. (pp. 10-23). New York: Springer.

Checkland P. (1981). Systems thinking, systems practice. Chichester, UK: John Wiley \& Sons.

Churchman C. W. (1971). The design of inquiring systems: Basic concepts of systems and organization. Basic Books: New York

Clarke, R. (2006). Key aspects of the history of the information systems discipline in Australia. Australasian Journal of Information Systems, 14(1), 123-140.

Davis, G. (2006). Information systems as an academic discipline: Looking back, looking forward, and enabling the future. In D. Avison, S. Elliot, J. Krogstie, \& J. Pries-Heje (Eds.), The past and future of information systems: 1976-2006 and beyond (pp. 11-25). Springer: Boston.

Davis, F. D. (1989). Perceived usefulness, perceived ease of use, and user acceptance of information technology. MIS Quarterly, 13(3), 319-340.

Davison, R. M., \& Martinsons, M. G. (2016). Context is king! Considering particularism in research design and reporting. Journal of Information Technology, 31(3), 241-249.

Delone, W. H. (1988). Determinants of success for computer usage in small businesses. MIS Quarterly, 12(1), 51-61.

Hirscheim, R., \& Klein, H. K. (2012). A glorious and not-so-short history of the information systems field. Journal of the AIS, 13(4),188-238.

Kling, R. (1980). Social analyses of computing: Theoretical perspectives in recent empirical research. ACM Computing Surveys, 12(1), 61-103.

Land, F. (2014). Early history of the information systems discipline in the UK: Account based on living through the period. Communications of the Association of Information Systems, 35, 319-333.

Langefors, B. (1977). Information systems theory. Information Systems, 2(4), 207-219.

Markus, M. L. (1999), Thinking the unthinkable: what happens if the IS field as we know it goes away?, in W. L. Currie and B. Galliers (eds), Rethinking management information systems, (pp. 175203), Oxford, UK: Oxford University Press.

Mumford, E., \& Weir, M. (1979). Computer systems in work design: The ETHICS method. Halstead Press: New York.

Orlikowski, W. J. \& Iacono, C. S. (2001). Research Commentary: Desperately seeking the "IT" in IT Research-a call to theorizing the IT artifact. Information Systems Research, 12(2), 121-134.

Qureshi, S. (2016). Creating a better world with information and communication technologies: Health equity. Information Technology for Development, 22(1),1-14.

Qureshi, S. (2015). Are we making a better world with information and communication technology for development (ICT4D) research? Findings from the field and theory building. Information Technology for Development, 21(4), 511-522.

Sahay, S. (2016). Are we building a better world with ICTs? empirically examining this question in the domain of public health in India. Information Technology for Development, 22(1), 168-176.

Sahay, S., Nicholson, B., \& Krishna, S. (2003). Global IT outsourcing: Software development across borders. Cambridge, UK: Cambridge University Press.

Sein, M. K., \& Harindranth, G. (2004). Conceptualizing the ICT artifact: Toward understanding the role of ICT in national development. The Information Society, 20(1), 15-24.

Sen, A. (1999). Development as freedom. New York: Anchor Books. 
Thapa, D., Sein, M. K., \& Sæbø, O. (2012). Building collective capabilities through ICT in a mountain region in Nepal: Where social capital leads to collective action. Information Technology for Development, 18(1), 5-22.

Walsham, G. (2005). Development, global futures and IS research: A polemic. Journal of Strategic Information Systems, 14(1), 5-15.

Walsham, G. (2017). ICT4D research: Reflections on history and future agenda. Journal of Information Technology for Development, 23(1), 18-41. 


\section{About the Authors}

Sundeep Sahay is a Professor of Information Systems at the University of Oslo, Norway. His broad research focus is in ICTs for Development, and over the last two decades or so has specialized in the domain of public health information systems in developing countries. His areas of work span research, education and policy and practice. He has been engaged in influencing global health policy through work with WHO, UN FAO, Asian Development Bank, and various National Ministries of Health spanning about 20 countries. He is the founder of a NGO in India called HISP India which has been supporting the adoption, implementation and use of open source health information systems for the public sector in various Asian countries, and continues till date to mentor its evolution in an honorary capacity. His research interests are multi-disciplinary spanning disciplines of information systems, development studies, public health, organization studies, and the sociology and philosophy of technology.

Maung Sein is Professor of Information Systems at the University of Agder, Norway, and Visiting Professor at Luleå University of Technology, Sweden. He has published extensively in, among others, MIS Quarterly, Information Systems Research, The Information Society, Information Systems Journal and Information Technology for Development Journal. He has conducted research and conducted workshops and seminars in several developing countries and has presented his work in conferences including International Conference on Information Systems and biennial conferences of IFIP W.G. 9.4 (Social Implications of Computers in Developing Countries). He is a former Senior Editor of Journal of AIS, and his other editorial board experiences include MIS Quarterly, MISQ Executive, Information Systems Journal, and guest-editing Communications of the ACM and Scandinavian Journal of IS. He co-founded of the AIS Special Interest Group on e-Government and is a former chair of IFIP W.G. 9.4.

Cathy Urquhart is Professor of Digital and Sustainable Business at Manchester Metropolitan University Business School. She is the author of Grounded Theory for Qualitative Research (for details, see http://www.uk.sagepub.com/books/Book232280). She is a previous Senior Editor for MIS Quarterly,and an Associate Editor for Information Technology and Development. Her honors and awards include the AIS Volunteer Spotlight for Outstanding Contributions to Membership Services in 2008, MIS Quarterly Most Developmental Associate Editor in 2007, Best Paper Award Journal of the Association of Information Systems (with Antonio Diaz Andrade and Tiru Arthanari) in 2015. She is a founding member of the AIS Womens College, and co-chaired the ICIS Womens Breakfast from 2010 to 2013. She was ICIS coprogram chair for ICIS 2015 in Fort Worth, Texas. She is a member of the AIS College of Senior Scholars. She has a strong interest in the use of grounded theory in information systems and has written extensively on this topic. Her website can be found here https://www2.mmu.ac.uk/business-school/about-us/ourstaff/otehm/profile/index.php?id=899 and her email address is c.urquhart@mmu.ac.uk.

Copyright $(02017$ by the Association for Information Systems. Permission to make digital or hard copies of all or part of this work for personal or classroom use is granted without fee provided that copies are not made or distributed for profit or commercial advantage and that copies bear this notice and full citation on the first page. Copyright for components of this work owned by others than the Association for Information Systems must be honored. Abstracting with credit is permitted. To copy otherwise, to republish, to post on servers, or to redistribute to lists requires prior specific permission and/or fee. Request permission to publish from: AIS Administrative Office, P.O. Box 2712 Atlanta, GA, 30301-2712 Attn: Reprints or via email from publications@aisnet.org. 